\title{
Preparation of Tin Oxide Quantum Dots in Aqueous Solution and Applications in Semiconductor Gas Sensors
}

\author{
Jianqiao Liu ${ }^{1}$, Weiting Xue ${ }^{1}$, Guohua Jin ${ }^{1}$, Zhaoxia Zhai ${ }^{1, *}$, Jiarong Lv $^{1}$, Wusong Hong ${ }^{1}$ \\ and Yuzhen Chen ${ }^{2}$ \\ 1 College of Information Science and Technology, Dalian Maritime University, Dalian 116026, China; \\ jqliu@dlmu.edu.cn (J.L.); jessxwt@sina.com (W.X.); jingh@dlmu.edu.cn (G.J.); jiaronglv@outlook.com (J.Lv.); \\ hongwusong@outlook.com (W.H.) \\ 2 Department of Material Science and Engineering, Dalian Maritime University, Dalian 116026, China; \\ cyz7817@dlmu.edu.cn \\ * Correspondence: shirlyllei@dlmu.edu.cn; Tel.: +86-4-118-472-9934
}

Received: 20 January 2019; Accepted: 7 February 2019; Published: 11 February 2019

\begin{abstract}
Tin oxide quantum dots (QDs) were prepared in aqueous solution from the precursor of tin dichloride via a simple process of hydrolysis and oxidation. The average grain size of QDs was $1.9 \mathrm{~nm}$. The hydrothermal treatment was used to control the average grain size, which increased to 2.7 and $4.0 \mathrm{~nm}$ when the operating temperatures of 125 and $225^{\circ} \mathrm{C}$ were employed, respectively. The X-ray photoelectron spectroscopy (XPS) spectrum and X-ray diffraction analysis (XRD) pattern confirmed a rutile $\mathrm{SnO}_{2}$ system for the QDs. A band gap of $3.66 \mathrm{eV}$ was evaluated from the UV-VIS absorption spectrum. A fluorescence emission peak was observed at a wavelength of $300 \mathrm{~nm}$, and the response was quenched by the high concentration of QDs in the aqueous solution. The current-voltage (I-V) correlation inferred that grain boundaries had the electrical characteristics of the Schottky barrier. The response of the QD thin film to $\mathrm{H}_{2}$ gas revealed its potential application in semiconductor gas sensors.
\end{abstract}

Keywords: tin oxide; quantum dot; aqueous solution; semiconductor; gas sensor

\section{Introduction}

The semiconductor quantum dot (QD) is a very small three-dimensional system with dimensions of several nanometers. It is constituted by a few hundred atoms, much fewer than the atom number of a bulk system. Because of the small size of QDs, the energy states for electrons, holes, and excitons are discrete series, revealing the effect of quantum confinement. They bring unique characteristics that are valuable for producing advantageous electronic devices. Thus, in recent decades, QDs have attracted a lot of attention. For example, Alberto prepared PbS QDs for photoconductors, in which the control of surface chemistry offered a direct approach for the tuning of charge carrier dynamics based on strongly coupled QD solids [1]. Ternary alloy PbCdS QDs were explored as photosensitizers for quantum dot sensitized solar cells [2]. CdSe QDs were used as ultrasensitive sensors for $\mathrm{Pb}^{2+}$ heavy metal ions [3] and fluorescent nanomarkers for diesel oil [4]. Colloidal QDs of $\mathrm{PbS}, \mathrm{ZnO}$, and $\mathrm{WO}_{3}$ were good candidates for novel semiconductor gas sensors [5-9]. Even though the semiconductor QDs of CdSe, PbS, and CdS showed perspectives in the practical applications, their toxicities have to be considered. The elements of cadmium, lead, and telluride have been proved to be harmful to many kinds of living things, especially after their accumulation through the food web [10].

Tin oxide $\left(\mathrm{SnO}_{2}\right)$ is a classical semiconductor, which has a wide direct band gap of $3.6 \mathrm{eV}$. It holds the advantages of good chemical stability, non-toxicity, and low cost. Recently, dozens of works have 
been published to report the applications of $\mathrm{SnO}_{2}$ QDs in novel electronic devices of gas sensors [11-17], photocatalysts [18,19], solar cells [20,21], and lithium-ion batteries [22,23]. Many techniques have been developed to prepare QD elements and devices, such as molecular beam epitaxy, metal-organic chemical vapor deposition, and some chemical routes [24]. However, these methods relied on complex facilities, or included organic compounds, which may bring potential toxicity to human beings or the environment. For example, $\mathrm{SnO}_{2}$ QDs were synthesized via a solvothermal route, in which organic reagents of oleic acid, oleylamine, and toluene were used [25,26]. Bathula prepared $\mathrm{SnO}_{2}$ QDs from the precursor of tin chloride pentahydrate with the aid of hydrazine and ethanol [27]. The consumption of toxic organics in the QD fabrication process not only put employees in danger but also increased the cost in environmental remediation by factories. Therefore, a simple and cheap method to prepared $\mathrm{SnO}_{2}$ QDs is expected.

In the present work, $\mathrm{SnO}_{2}$ QDs were prepared in aqueous solution via a simple route of hydrolysis and oxidation of $\mathrm{SnCl}_{2} \cdot 2 \mathrm{H}_{2} \mathrm{O}$, with the catalytic of $\mathrm{CH}_{4} \mathrm{~N}_{2} \mathrm{~S}$. The hydrothermal treatment was introduced to control the grain growth of QDs. The characteristics of composition, morphology, grain size, photonic adsorption, fluorescence spectrum, and electrical property were concluded for the prepared QDs.

\section{Materials and Methods}

$\mathrm{SnCl}_{2} \cdot 2 \mathrm{H}_{2} \mathrm{O}$ of $0.01 \mathrm{~mol}$ and $\mathrm{CH}_{4} \mathrm{~N}_{2} \mathrm{~S}$ of $0.001 \mathrm{~mol}$ were dissolved into deionized water of $50 \mathrm{ml}$ by a magnet stirring apparatus in order to acquire a solution, which was stirred for $24 \mathrm{~h}$ at $25^{\circ} \mathrm{C}$. The starting material of $\mathrm{SnCl}_{2} \cdot 2 \mathrm{H}_{2} \mathrm{O}$ was transformed to $\mathrm{SnO}_{2}$ QDs after hydrolysis and oxidation, which were promoted by the existence of $\mathrm{CH}_{4} \mathrm{~N}_{2} \mathrm{~S}$, as shown in Equation (1) and Equation (2). It was proved that this process was spontaneous but the resultant was not stable $[28,29] . \mathrm{CH}_{4} \mathrm{~N}_{2} \mathrm{~S}$ acted as stabilizer and accelerator because of the tautomerism between thiourea and isothiourea in the acidic solution [30,31]. It therefore consumed the $\mathrm{HCl}$ and accelerated the ongoing of Equation (1) as well as the formation of $\mathrm{SnO}_{2}$ QDs.

$$
\begin{aligned}
& \mathrm{SnCl}_{2}+2 \mathrm{H}_{2} \mathrm{O} \rightarrow \mathrm{Sn}(\mathrm{OH})_{2}+2 \mathrm{HCl} \\
& 2 \mathrm{Sn}(\mathrm{OH})_{2}+\mathrm{O}_{2} \rightarrow 2 \mathrm{SnO}_{2}+2 \mathrm{H}_{2} \mathrm{O}
\end{aligned}
$$

The obtained $\mathrm{SnO}_{2}$ QD solution was tagged as QD0, and it was put into the polyphenylene autoclave for hydrothermal treatment at 125 and $225{ }^{\circ} \mathrm{C}$ for $2 \mathrm{~h}$, with QD125 and QD225 tags for the corresponding samples, respectively. The QD solutions were dried to obtain powders for compositional and optical characterizations. The QD0 solution was deposited on alumina substrates with silver electrodes, which were described in previous work [12]. The deposition process of QD thin film comprised a spin-coating at $1000 \mathrm{rpm}$ and a subsequent heat treatment at $150{ }^{\circ} \mathrm{C}$ for $10 \mathrm{~min}$. The deposition was repeated five times, and the obtained thin film was used for characterization of electrical and gas-sensing properties.

The morphology of $\mathrm{SnO}_{2}$ QDs were observed by transmission electron microscopy (TEM, JEM-3200FS, JEOL, Tokyo, Japan). The QD size distribution was obtained by dynamic light scattering (DLS, Zetasizer Nano ZS 90, Malvern panalytical Ltd., Malvern, UK). The dried powders were prepared for X-ray diffraction analysis (XRD, D/MAX-Ultima, Rigaku, Tokyo, Japan), X-ray photoelectron spectroscopy (XPS, ESCALAB 250 XI, ThermoFisher Scientific, Waltham, MA, USA), and ultraviolet-visible spectroscopy (UV-VIS, UH4150 Spectrophotometer, Hitachi, Tokyo, Japan). The fluorescence spectra of the QD0 solution and its diluted one were collected by a fluorescence spectrometer (FLS-980, Edinburgh Instruments, Edinburgh, UK). The electrical property and gas-sensing characteristics of QD0 thin films were measured by Keithley 2450 (Tektronix, Beaverton, OR, USA). The sensor response $(S)$ was defined as the ratio of the thin film resistance in air $\left(R_{a}\right)$ to the ratio in the reducing gas $\left(R_{g}\right)$, as $S=R_{a} / R_{g} . \mathrm{H}_{2}$ was used as the representative of reducing target gases in order to check the gas-sensing characteristics of $\mathrm{SnO}_{2}$ QDs. 


\section{Results}

Figure 1 illustrates the morphologies of $\mathrm{SnO}_{2}$ QDs from TEM observation, which shows the average grain sizes of $1.9 \pm 0.2,2.7 \pm 0.4$, and $3.9 \pm 0.8 \mathrm{~nm}$ for QD0, QD125, and QD225 samples, respectively. The grains appeared to be uniform in size. QD0 and QD125 samples dispersed well in the aqueous solution, while a little aggregation was found in the QD225 sample. The characteristic spacing of $0.33 \mathrm{~nm}$ was observed, corresponding to the (110) planes of the rutile phase of $\mathrm{SnO}_{2}$.

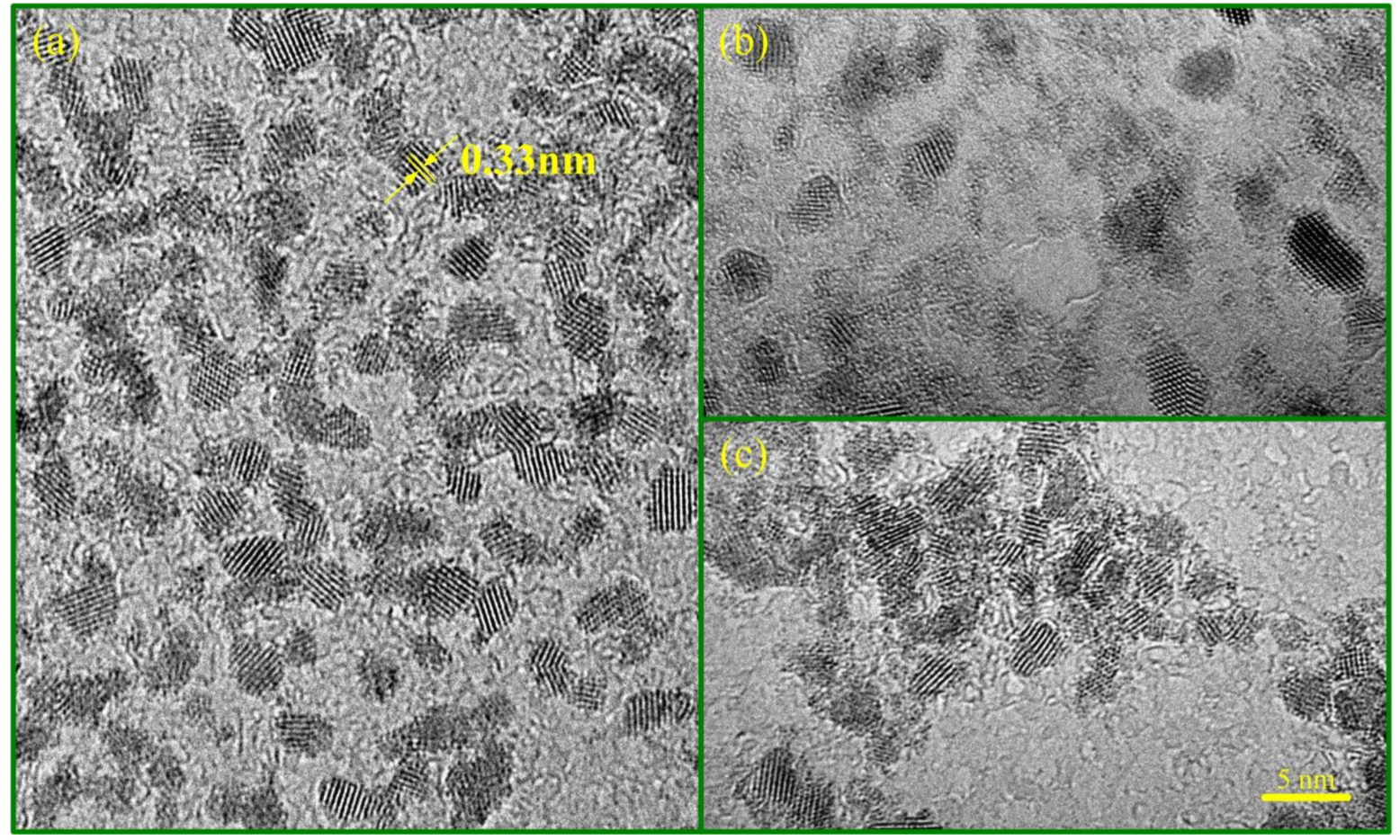

Figure 1. Transmission electron microscope morphologies of quantum dot (QD) samples: (a) QD0, (b) QD125, and (c) QD225.

The XRD patterns of QD0, QD125, and QD225 samples are revealed in Figure 2, in which the standard pattern of $\mathrm{SnO}_{2}$ peaks [32] was also involved. An extremely weak peak was observed for the (211) plane of the QD0 sample. After the hydrothermal treatment at $125^{\circ} \mathrm{C}$, the grain growth happened as the obvious (211) peak appeared. The whole $\mathrm{SnO}_{2}$ peak pattern was found when the temperature of hydrothermal treatment increased to $225^{\circ} \mathrm{C}$, as shown by the QD225 sample, which showed a complete crystal structure of the rutile $\mathrm{SnO}_{2}$ system. The crystallite size of each sample was calculated by the Scherrer's formula based on the (211) peak. The QD125 and QD225 samples had crystallite sizes of $2.8 \mathrm{~nm}$ and $4.2 \mathrm{~nm}$, respectively, while the crystallite size was less than $2.0 \mathrm{~nm}$ in the QD0 sample. The results were in agreement with the TEM observation. 


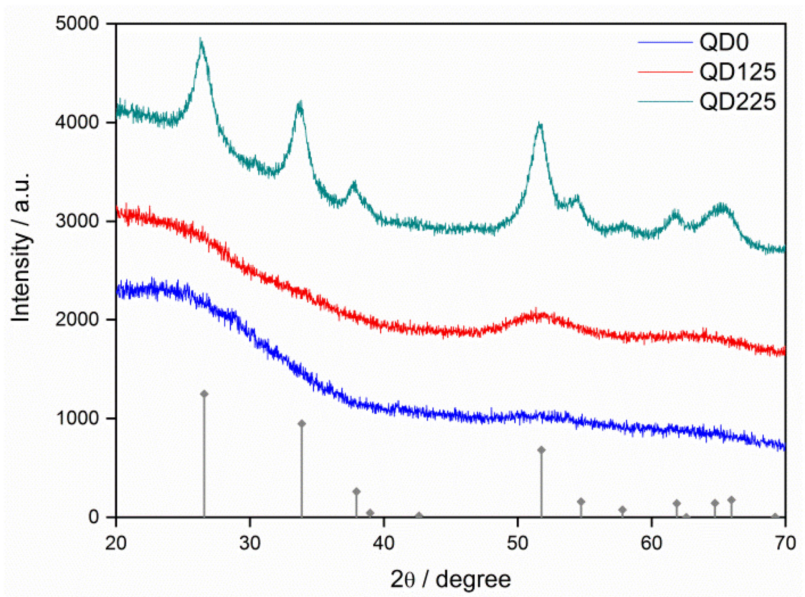

Figure 2. X-ray diffraction patterns of QD0, QD125, and QD225 samples with the standard pattern of $\mathrm{SnO}_{2}$ semiconductors.

Figure 3 shows the size distributions of QD0, QD125, and QD225 samples in aqueous solution. The peaks appeared at $4.8,5.6$, and $6.5 \mathrm{~nm}$, shifting to larger sizes with the incremental temperature of the hydrothermal process. The average grain sizes were $5.3 \pm 1.1,5.8 \pm 0.9$, and $8.0 \pm 5.9 \mathrm{~nm}$, respectively, and the results were larger than the ones from TEM observation and the XRD calculation. The results of TEM, XRD, and DLS showed that hydrothermal treatment is an effective way to control the grain size of $\mathrm{SnO}_{2}$ QDs. The grains grew up in the aqueous solution by combining tiny crystallites of $\mathrm{SnO}_{2}$, and the higher temperature of hydrothermal treatment provided more energy for combination. Therefore, it was possible to prepare desired QDs with controllable grain sizes by adjusting the temperature and time of hydrothermal treatment.

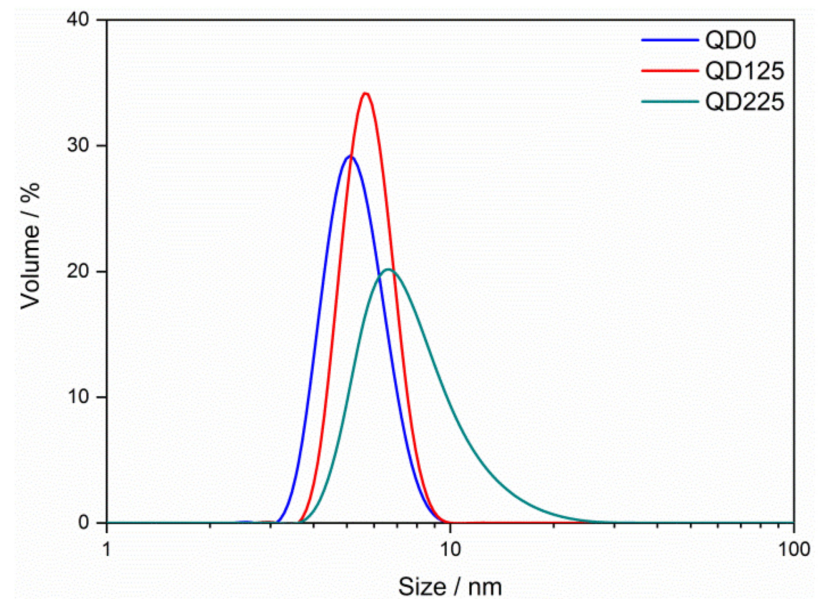

Figure 3. Size distributions of QD0, QD125, and QD225 samples in aqueous solution.

Figure 4a shows the survey XPS spectrum of the QD0 sample, which performed the existence of C, O, and Sn elements. Two peaks of 487.3 and $495.6 \mathrm{eV}$ were observed in the high solution pattern of $\mathrm{Sn} 3 \mathrm{~d}$, corresponding to $\mathrm{Sn} 3 \mathrm{~d}_{3 / 2}$ and $\mathrm{Sn} 3 \mathrm{~d}_{5 / 2}$, as shown in Figure $4 \mathrm{c}$. Meanwhile, the peak of $\mathrm{O} 1 \mathrm{~s}$ appeared at $531.5 \mathrm{eV}$, as shown in Figure $4 \mathrm{~b}$. The results coincided with the standard pattern from the rutile $\mathrm{SnO}_{2}$ system $[33,34]$. 


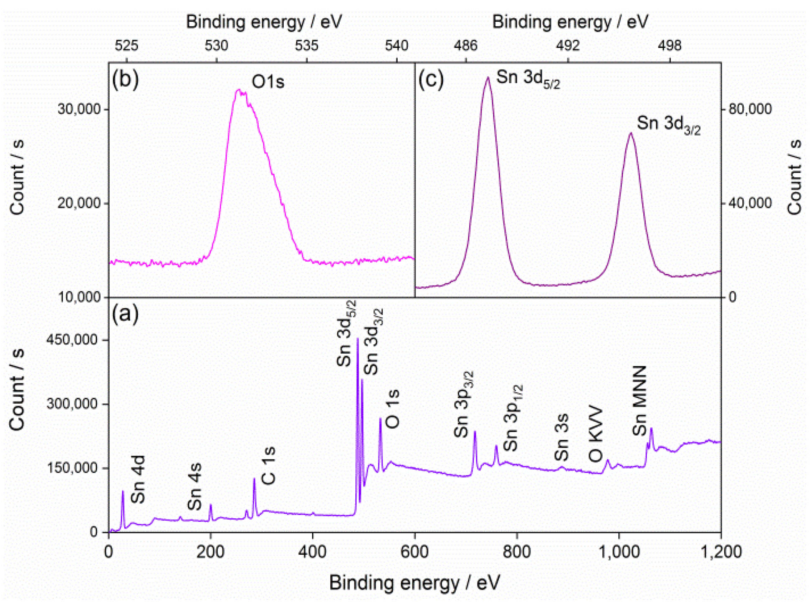

Figure 4. X-ray photoelectron spectrum of the QD0 sample: (a) Survey and high-solution peaks of (b) O 1s and (c) Sn 3d.

The UV-VIS absorption spectrum of the QD0 sample is shown in Figure 5, which shows two absorption peaks. The spectrum was transformed and plotted in the coordinates of $(\alpha h v)^{2}$ against $h v$ in order to evaluate the band gap $\left(E_{g}\right)$. The $E_{g}$ was calculated to be $3.66 \mathrm{eV}$, with a slight increase compared to $3.6 \mathrm{eV}$ of the bulk $\mathrm{SnO}_{2}$ material. The $E_{g}$ increase of $\mathrm{SnO}_{2}$ QDs was also concluded in other works $[13,25,35]$. However, the evaluated $E_{g}$ was smaller than the ones in the previous reports for QDs with similar sizes. The defects in the crystal lattice, such as oxygen vacancies, were potentially responsible for the slight enhancement of $E_{g}$.

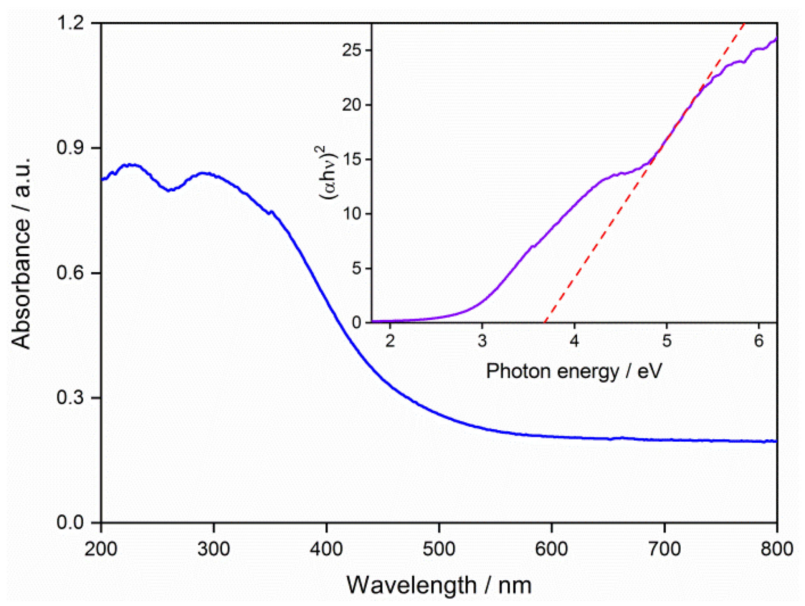

Figure 5. Ultraviolet-visible absorption spectrum of the QD0 sample and the evaluation of band gap $\left(E_{g}\right)$.

The fluorescence spectra of the QD0 sample with the concentration of 0.2 and $0.002 \mathrm{~mol} / \mathrm{L}$ are shown in Figure 6. The emission peaks at $300 \mathrm{~nm}$ were in agreement with the previous report [36]. The fluorescence quenching was observed when the concentration was as high as $0.2 \mathrm{~mol} / \mathrm{L}$. In this case, the fluorescence emission was inhibited by the nearby grains, which adsorbed the energy of electron transition from conduction band to valence band. It was ascribed to the self-quenching of fluorescence, which is the strong coupling of ground state fluorescence agents creating a stable, non-fluorescent complex [37]. The fluorescence self-quenching was driven by hydrophobic effects or $\pi-\pi$ stacking of fluorescence agents at high concentrations [38]. 


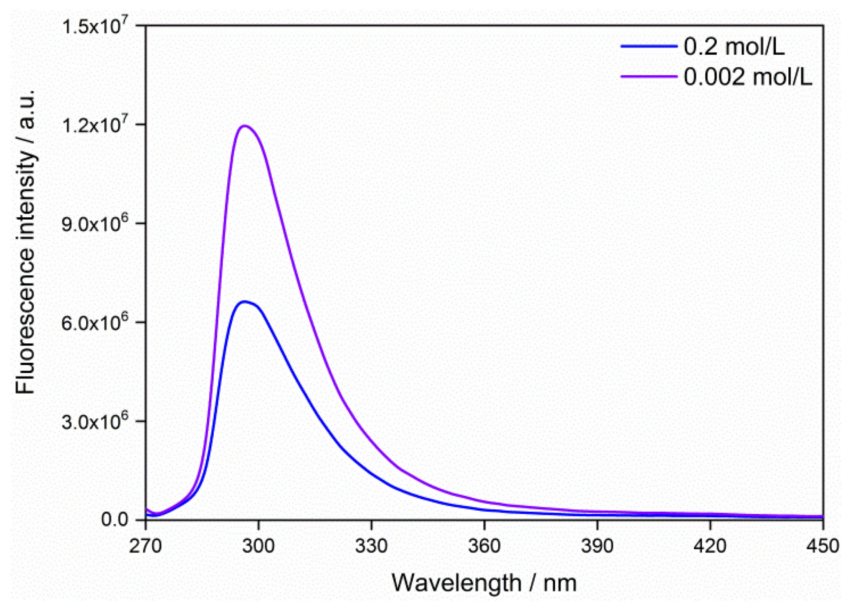

Figure 6. Fluorescence spectra of the QD0 sample with concentration of 0.2 and $0.002 \mathrm{~mol} / \mathrm{L}$.

Figure 7 shows the voltage-current characteristics of the thin film, which was prepared from the QD0 solution. An approximately linear curve was observed between 0 and 4 V. A sharp increase took place when the voltage increased to 4-5 V. In this case, the depletion layer disappeared under the effect of an external biased electric field. The tendency of the curve was similar to the nanocrystalline $\mathrm{SnO}_{2}$ thin films with Schottky barrier at grain boundaries [39], revealing that the electrical properties of the QD thin film were also determined by the depletion layer.

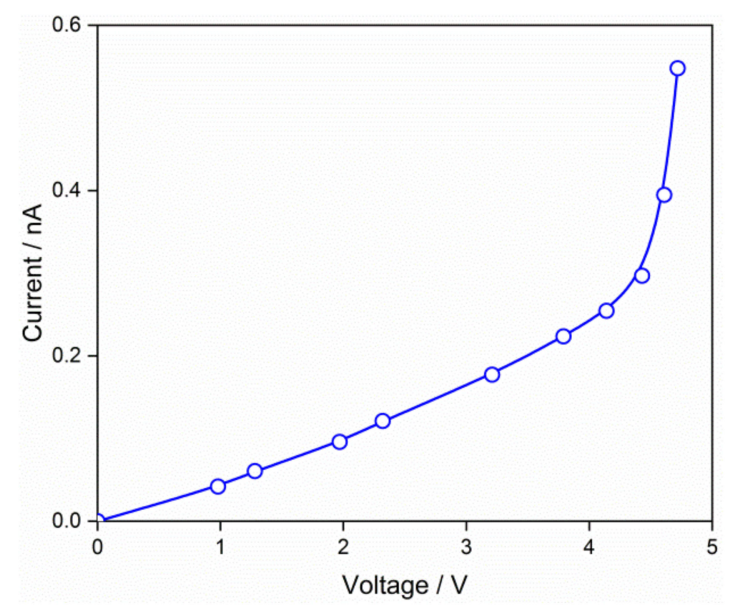

Figure 7. Voltage-current characteristics of the thin film prepared from the QD0 solution.

Figure 8 shows the dynamic response of the QD0 thin film at room temperature to the $\mathrm{H}_{2}$ gas with concentration of 133 and 1333 ppm, to which the responses are 16.1 and 35.5. After exposure to the reducing gas, the resistance of thin film decreased, because the reducing gas molecules consumed the adsorbed oxygen on the grain surface. The results show that the $\mathrm{SnO}_{2}$ gas sensor benefited from the structure of the QDs. Van Toan [40] used to fabricate $\mathrm{SnO}_{2}$ nanocrystalline gas sensors with grain size of $20 \mathrm{~nm}$, which showed a response of 6 to $1000 \mathrm{ppm} \mathrm{H}_{2}$ at $300{ }^{\circ} \mathrm{C}$. Kim [41] recently prepared $\mathrm{SnO}_{2}$ nanowire-based gas sensors, and the response of bare $\mathrm{SnO}_{2}$ nanowires was 8 to $100 \mathrm{ppm} \mathrm{H}_{2}$ at $300{ }^{\circ} \mathrm{C}$. Therefore, the prepared QDs were the promising candidate for producing novel semiconductor gas sensors, which were highly sensitive at room temperature. In this work, however, only the gas of $\mathrm{H}_{2}$ was used to check the gas-sensing performance of QDs, as was the same operation in much other research $[42,43]$. It is known that the semiconductor gas sensors would show response to other gases, such as $\mathrm{CO}, \mathrm{NO}_{2}$, ammonia, and acetone [44]. Thus, selectivity was one of the sensor properties that had to be concerned. The sensor properties were also found to be dependent on the characteristics of 
QDs, including grain size and shape [45-48]. Further investigations are expected to reveal the details of gas-sensing performances, including the grain size effect and selectivity of the semiconductor QDs.

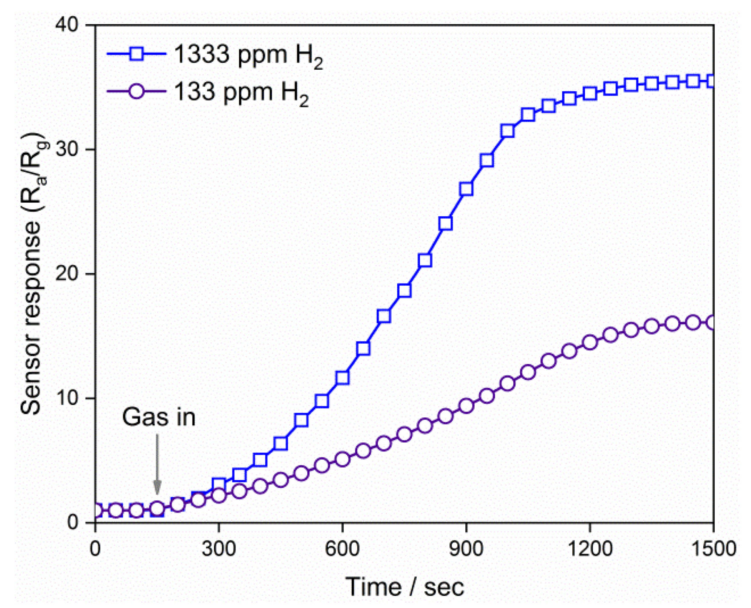

Figure 8. Gas-sensing characteristics of the thin film prepared from the QD0 solution at room temperature.

\section{Conclusions}

The $\mathrm{SnO}_{2}$ QDs were prepared in the aqueous solution via a simple process of hydrolysis and oxidation. The average grain size was $1.9 \mathrm{~nm}$, and it increased to 2.7 and $4.0 \mathrm{~nm}$ after the hydrothermal treatments at 125 and $225^{\circ} \mathrm{C}$, respectively. The rutile $\mathrm{SnO}_{2}$ system was confirmed by the XPS spectrum and the XRD pattern. UV-VIS absorption spectrum results had an $E_{g}$ value of $3.66 \mathrm{eV}$, which is a little larger than the bulk $\mathrm{SnO}_{2}$ system. The QDs of $0.002 \mathrm{~mol} / \mathrm{L}$ showed a fluorescence emission peak at the wavelength of $300 \mathrm{~nm}$, and their fluorescence response was quenched when the high concentration of $0.2 \mathrm{~mol} / \mathrm{L}$ was used. The voltage-current characteristics showed that the electrical properties of the QD thin film were determined by the depletion layer, where a Schottky barrier was established at the grain boundaries. The QD thin film showed responses of 16.1 and 35.5 to $\mathrm{H}_{2}$ gas with concentration of 133 and 1333 ppm, respectively.

Author Contributions: Methodology, J.Lv.; investigation, J.Lv., W.X., J.Lv., and W.H.; writing—original draft preparation, J.Lv. \& W.X.; writing-review and editing, Z.Z. \& G.J.; supervision, Y.C.; project administration, J.Lv. \& G.J.; funding acquisition, J.Lv.

Funding: This work was financially supported by the National Natural Science Foundation of China (Grant No. 11704055), the Liaoning Natural Science Foundation (Grant No. 20180510021), the Dalian High-Level Talents Innovation Supporting Program (Grant No. 2017RQ073), and the Fundamental Research Funds for the Central Universities (Grant No. 3132018188, 3132016320, and 3132016347).

Conflicts of Interest: The authors declare no conflicts of interest.

\section{References}

1. Maulu, A.; Navarro-Arenas, J.; Rodríguez-Cantó, P.J.; Sánchez-Royo, J.F.; Abargues, R.; Suárez, I.; Martínez-Pastor, J.P. Charge transport in trap-sensitized infrared PbS quantum-dot-based photoconductors: Pros and cons. Nanomaterials 2018, 8, 677. [CrossRef] [PubMed]

2. Yuan, C.; Li, L.; Huang, J.; Ning, Z.; Sun, L.; Ågren, H. Improving the photocurrent in quantum-dot-sensitized solar cells by employing alloy $\mathrm{Pb}_{x} \mathrm{Cd}_{1-x} \mathrm{~S}$ quantum dots as photosensitizers. Nanomaterials 2016, 6, 97. [CrossRef] [PubMed]

3. Mohamed, A.E.; Yuangang, Z.; Hsiao-Hua, Y.; Ying, J.Y. Ultrasensitive $\mathrm{Pb}^{2+}$ detection by glutathione-capped quantum dots. Anal. Chem. 2007, 79, 9452-9458. [CrossRef] [PubMed]

4. Silva do Nascimento, A.; Cabral Filho, P.E.; Fontes, A.; Saegesser Santos, B.; Rodrigues de Carvalho, F.; Stragevitch, L.; Soares Leite, E. CdSe quantum dots as fluorescent nanomarkers for diesel oil. Fuel 2019, 239, 1055-1060. [CrossRef] 
5. Zhang, B.; Li, M.; Song, Z.; Kan, H.; Yu, H.; Liu, Q.; Zhang, G.; Liu, H. Sensitive $\mathrm{H}_{2} \mathrm{~S}$ gas sensors employing colloidal zinc oxide quantum dots. Sens. Actuators B 2017, 249, 558-563. [CrossRef]

6. Liu, H.; Li, M.; Shao, G.; Zhang, W.; Wang, W.; Song, H.; Cao, H.; Ma, W.; Tang, J. Enhancement of hydrogen sulfide gas sensing of $\mathrm{PbS}$ colloidal quantum dots by remote doping through ligand exchange. Sens. Actuators B 2015, 212, 434-439. [CrossRef]

7. Li, M.; Luo, J.; Fu, C.; Kan, H.; Huang, Z.; Huang, W.; Yang, S.; Zhang, J.; Tang, J.; Fu, Y.; et al. PbSe quantum dots-based chemiresistors for room-temperature $\mathrm{NO}_{2}$ detection. Sens Actuators B 2018, 256, 1045-1056. [CrossRef]

8. Liu, H.; Li, M.; Voznyy, O.; Hu, L.; Fu, Q.; Zhou, D.; Xia, Z.; Sargent, E.H.; Tang, J. Physically flexible, rapid-response gas sensor based on colloidal quantum dot solids. Adv. Mater. 2014, 26, 2718-2724. [CrossRef]

9. Song, Z.; Huang, Z.; Liu, J.; Hu, Z.; Zhang, J.; Zhang, G.; Yi, F.; Jiang, S.; Lian, J.; Yan, J. Fully stretchable and humidity-resistant quantum dot gas sensors. ACS Sens. 2018, 3, 1048-1055. [CrossRef]

10. Zepeda, A.M.; Gonzalez, D.; Heredia, L.G.; Marquez, K.; Perez, C.; Pena, E.; Flores, K.; Valdes, C.; Eubanks, T.M.; Parsons, J.G. Removal of $\mathrm{Cu}^{2+}$ and $\mathrm{Ni}^{2+}$ from aqueous solution using $\mathrm{SnO}_{2}$ nanomaterial effect of: $\mathrm{pH}$, time, temperature, interfering cations. Microchem. J. 2018, 141, 188-196. [CrossRef]

11. Liu, J.; Lu, Y.; Cui, X.; Geng, Y.; Jin, G.; Zhai, Z. Gas-sensing properties and sensitivity promoting mechanism of $\mathrm{Cu}$-added $\mathrm{SnO}_{2}$ thin films deposited by ultrasonic spray pyrolysis. Sens. Actuators B 2017, 248, 862-867. [CrossRef]

12. Liu, J.; Liu, X.; Zhai, Z.; Jin, G.; Jiang, Q.; Zhao, Y.; Luo, C.; Quan, L. Evaluation of depletion layer width and gas-sensing properties of antimony-doped tin oxide thin film sensors. Sens. Actuators B 2015, 220, 1354-1360. [CrossRef]

13. Song, Z.; Liu, J.; Liu, Q.; Yu, H.; Zhang, W.; Wang, Y.; Huang, Z.; Zang, J.; Liu, H. Enhanced $\mathrm{H}_{2} \mathrm{~S}$ gas sensing properties based on $\mathrm{SnO}_{2}$ quantum wire/reduced graphene oxide nanocomposites: Equilibrium and kinetics modeling. Sens. Actuators B 2017, 249, 632-638. [CrossRef]

14. Liu, H.; Zhang, W.; Yu, H.; Liang, G.; Song, Z.; Xu, S.; Min, L.; Yang, W.; Song, H.; Jiang, T. Solution-processed gas sensors employing $\mathrm{SnO}_{2}$ quantum dot/MWCNT Nanocomposites. ACS Appl. Mater. Interfaces 2016, 8, 840. [CrossRef] [PubMed]

15. Liu, J.; Wang, W.; Zhai, Z.; Jin, G.; Chen, Y.; Hong, W.; Wu, L.; Gao, F. Influence of oxygen vacancy behaviors in cooling process on semiconductor gas sensors: A numerical analysis. Sensors 2018, 18, 3929. [CrossRef] [PubMed]

16. Liu, J.; Wang, W.; Zhai, Z.; Jin, G.; Chen, Y. Numerical analysis of the effect of the cooling process on the characteristics of n-type semiconductor gas sensors. J. Comput. Electron. 2018. [CrossRef]

17. Liu, J.; Gao, Y.; Wu, X.; Jin, G.; Zhai, Z.; Liu, H. Inhomogeneous oxygen vacancy distribution in semiconductor gas sensors: Formation, migration and determination on gas sensing characteristics. Sensors 2017, 17, 1852. [CrossRef]

18. Zhao, D.; Wu, X. Nanoparticles assembled $\mathrm{SnO}_{2}$ nanosheet photocatalysts for wastewater purification. Mater. Lett. 2018, 210, 354-357. [CrossRef]

19. Tammina, S.K.; Mandal, B.K.; Khan, F.N. Mineralization of toxic industrial dyes by gallic acid mediated synthesized photocatalyst $\mathrm{SnO}_{2}$ nanoparticles. Environ. Technol. Innov. 2019, 13, 197-210. [CrossRef]

20. Jayaweera, E.N.; Kumara, G.R.A.; Kumarage, C.; Ranasinghe, S.K.; Rajapakse, R.M.G.; Bandara, H.M.N.; Ileperuma, O.A.; Dassanayake, B.S. CdS nanosheet-sensitized solar cells based on $\mathrm{SnO}_{2} / \mathrm{MgO}$ composite films. J. Photochem. Photobiol. A 2018, 364, 109-115. [CrossRef]

21. Zhang, X.; Rui, Y.; Yang, J.; Wang, L.; Wang, Y.; Xu, J. Monodispersed $\mathrm{SnO}_{2}$ microspheres aggregated by tunable building units as effective photoelectrodes in solar cells. Appl. Surf. Sci. 2019, 463, 679-685. [CrossRef]

22. Min, X.; Sun, B.; Chen, S.; Fang, M.; Wu, X.; Liu, Y.G.; Abdelkader, A.; Huang, Z.; Liu, T.; Xi, K.; et al. A textile-based $\mathrm{SnO}_{2}$ ultra-flexible electrode for lithium-ion batteries. Energy Storage Mater. 2019, 16, 597-606. [CrossRef]

23. Li, H.; Su, Q.; Kang, J.; Huang, M.; Feng, M.; Feng, H.; Huang, P.; Du, G. Porous $\mathrm{SnO}_{2}$ hollow microspheres as anodes for high-performance lithium ion battery. Mater. Lett. 2018, 217, 276-280. [CrossRef]

24. Hollingsworth, J.A. Semiconductor Nanocrystal Quantum Dots; John Wiley \& Sons, Ltd.: Hoboken, NJ, USA, 2006. 
25. Song, Z.; Xu, S.; Liu, J.; Hu, Z.; Gao, N.; Zhang, J.; Yi, F.; Zhang, G.; Jiang, S.; Liu, H. Enhanced catalytic activity of $\mathrm{SnO}_{2}$ quantum dot films employing atomic ligand-exchange strategy for fast response $\mathrm{H}_{2} \mathrm{~S}$ gas sensors. Sens. Actuators B 2018, 271, 147-156. [CrossRef]

26. Liu, H.; Xu, S.; Min, L.; Gang, S.; Song, H.; Zhang, W.; Wei, W.; He, M.; Liang, G.; Song, H. Chemiresistive gas sensors employing solution-processed metal oxide quantum dot films. Appl. Phys. Lett. 2014, 105, 766. [CrossRef]

27. Babu, B.; Neelakanta Reddy, I.; Yoo, K.; Kim, D.; Shim, J. Bandgap tuning and XPS study of $\mathrm{SnO}_{2}$ quantum dots. Mater. Lett. 2018, 221, 211-215. [CrossRef]

28. Han, W.-Q.; Zettl, A. Coating single-walled carbon nanotubes with tin oxide. Nano Lett. 2003, 3, 681-683. [CrossRef]

29. Cigala, R.M.; Crea, F.; de Stefano, C.; Lando, G.; Milea, D.; Sammartano, S. The inorganic speciation of tin(II) in aqueous solution. Geochim. Cosmochim. Acta 2012, 87, 1-20. [CrossRef]

30. Misra, G.S.; Gupta, C.V. Aqueous polymerization of methacrylamide initiated by acidified bromate/thiourea redox system. Die Makromol. Chem. 1973, 168, 105-118. [CrossRef]

31. Swaminathan, K.; Irving, H.M.N.H. Infra-red absorption spectra of complexes of thiourea. J. Inorg. Nucl. Chem. 1964, 26, 1291-1294. [CrossRef]

32. Seki, H.; Ishisawa, N.; Mizutani, N.; Kato, M. High temperature structures of the rutile-type oxides, $\mathrm{TiO}_{2}$ and $\mathrm{SnO}_{2}$. J. Ceram. Assoc. Jpn. 1984, 92, 219-223. [CrossRef]

33. Barreca, D.; Garon, S.; Tondello, E.; Zanella, P. $\mathrm{SnO}_{2}$ nanocrystalline thin films by XPS. Surf. Sci. Spectra 2000, 7, 81-85. [CrossRef]

34. Stranick, M.A.; Moskwa, A. $\mathrm{SnO}_{2}$ by XPS. Surf. Sci. Spectra 1993, 2, 50-54. [CrossRef]

35. Song, Z.; Wei, Z.; Wang, B.; Zhen, L.; Xu, S.; Zhang, W.; Yu, H.; Min, L.; Zhao, H.; Zang, J. Sensitive room-temperature $\mathrm{H}_{2} \mathrm{~S}$ gas sensors employing $\mathrm{SnO}_{2}$ quantum wire/reduced graphene oxide nanocomposites. Chem. Mater. 2016, 28, 1205-1212. [CrossRef]

36. Henry, J.; Mohanraj, K.; Sivakumar, G.; Umamaheswari, S. Electrochemical and fluorescence properties of $\mathrm{SnO} 2$ thin films and its antibacterial activity. Spectrochim. Acta Part A 2015, 143, 172-178. [CrossRef] [PubMed]

37. Lakowicz, J.R. Quenching of Fluorescence. In Principles of Fluorescence Spectroscopy; Springer: New York, NY, USA, 2006; pp. 278-327.

38. Zhai, D.; Xu, W.; Zhang, L.; Chang, Y.-T. The role of "disaggregation" in optical probe development. Chem. Soc. Rev. 2014, 43, 2402-2411. [CrossRef] [PubMed]

39. Gong, S.; Liu, J.; Quan, L.; Fu, Q.; Zhou, D. Preparation of tin oxide thin films on silicon substrates via sol-gel routes and the prospects for the $\mathrm{H}_{2} \mathrm{~S}$ gas sensor. Sens. Lett. 2011, 9, 625-628. [CrossRef]

40. Van Toan, N.; Viet Chien, N.; Van Duy, N.; Si Hong, H.; Nguyen, H.; Duc Hoa, N.; Van Hieu, N. Fabrication of highly sensitive and selective $\mathrm{H}_{2}$ gas sensor based on $\mathrm{SnO}_{2}$ thin film sensitized with microsized Pd islands. J. Hazard. Mater. 2016, 301, 433-442. [CrossRef]

41. Kim, J.-H.; Mirzaei, A.; Kim, H.W.; Kim, S.S. Improving the hydrogen sensing properties of $\mathrm{SnO}_{2}$ nanowire-based conductometric sensors by Pd-decoration. Sens. Actuators B 2019, 285, 358-367. [CrossRef]

42. Sakai, G.; Matsunaga, N.; Shimanoe, K.; Yamazoe, N. Theory of gas-diffusion controlled sensitivity for thin film semiconductor gas sensor. Sens. Actuators B 2001, 80, 125-131. [CrossRef]

43. Xu, C.; Tamaki, J.; Miura, N.; Yamazoe, N. Grain size effects on gas sensitivity of porous $\mathrm{SnO}_{2}$-based elements. Sens. Actuators B 1991, 3, 147-155. [CrossRef]

44. Krivetskiy, V.; Ponzoni, A.; Comini, E.; Badalyan, S.; Rumyantseva, M.; Gaskov, A. Selectivity modification of $\mathrm{SnO}_{2}$-based materials for gas sensor arrays. Electroanalysis 2010, 22, 2809-2816. [CrossRef]

45. Yamazoe, N.; Shimanoe, K. Roles of shape and size of component crystals in semiconductor gas sensors II. Response to $\mathrm{NO}_{2}$ and $\mathrm{H}_{2}$. J. Electrochem. Soc. 2008, 155, J93-J98. [CrossRef]

46. Yamazoe, N.; Shimanoe, K. Roles of shape and size of component crystals in semiconductor gas sensors I. Response to oxygen. J. Electrochem. Soc. 2008, 155, J85-J92. [CrossRef] 
47. Liu, J.; Zhai, Z.; Jin, G.; Li, Y.; Monica, F.F.; Liu, X. Simulation of the grain size effect in gas-sensitive $\mathrm{SnO}_{2} \mathrm{thin}$ films using the oxygen vacancy gradient distribution model. Electron. Mater. Lett. 2015, 11, 34-40. [CrossRef]

48. Liu, J.; Jin, G.; Zhai, Z.; Monica, F.F.; Liu, X. Numeral description of grain size effects of tin oxide gas-sensitive elements and evaluation of depletion layer width. Electron. Mater. Lett. 2015, 11, 457-465. [CrossRef]

(C) 2019 by the authors. Licensee MDPI, Basel, Switzerland. This article is an open access article distributed under the terms and conditions of the Creative Commons Attribution (CC BY) license (http:/ / creativecommons.org/licenses/by/4.0/). 